$84 \%$, DLCO 50\%, walk distance $292 \mathrm{~m} .48 \%$ had oxygen desaturation on 6-minute walk. 47 patients $(26.9 \%)$ died. Mean followup was 19.8 months, median 14.4 months. 156 patients had $>12$ months follow-up and these were included in the prognostic evaluation.

Univariable survival analysis showed age, KBILD, FVC, DLCO, walk distance and exertional desaturation to have prognostic significance for all cause mortality. Univariable analysis of the sub-categories of the KBILD score showed the psychological $(\mathrm{p}=0.003)$ and breathlessness $(\mathrm{p}=0.002)$ domains to be significant, while the chest symptoms domain was not $(p=0.269)$.

After backwards stepwise selection the multivariable model contained age, KBILD, FVC and desaturation (Table 1). All included variables had prognostic significance.

AUROC analysis showed KBILD had equivalent sensitivity for 12-month mortality to FVC, DLCO and better sensitivity than walk distance (c-statistic in Table 1). A KBILD score of 34 had $75 \%$ sensitivity for 12 -month mortality, but only $10.5 \%$ specificity. Estimated median survival with KBILD of $<34$ was 9.7 months, compared to 36.4 months for KBILD > 34 ( $\mathrm{p}=0.02$ ). Conclusions In this cohort, the KBILD has equivalent prognostic power in ILD to pulmonary physiology and exercise testing at a single point in time. It is important to assess HRQL to give ILD patients optimal prognostic information.

\section{S21 IDENTIFICATION OF CLINICAL PROGNOSTIC PARAMETERS IN PATIENTS WITH IDIOPATHIC PULMONARY FIBROSIS}

K Rogers, C Hadinnapola, K Sylvester, M Toshner, H Parfrey. Papworth Hospital, Cambridge, UK

\subsection{6/thoraxjnl-2016-209333.27}

Idiopathic Pulmonary Fibrosis (IPF) is a progressive, scarring lung disease with a poor prognosis and median survival of 3 years. It is a heterogeneous disorder with varying rates of progression which presents a challenge for accurate prognostic prediction. The composite physiologic index (CPI) and the Gender, Age and Physiology (GAP) score are validated scoring systems for prognostic determination in IPF. Our data suggest these scoring systems have limited usefulness and we have undertaken a modelling approach to evaluate clinical prognostic parameters.

Methods Gender, age, smoking history, presence of emphysema on HRCT thorax and echocardiogram confirmed pulmonary

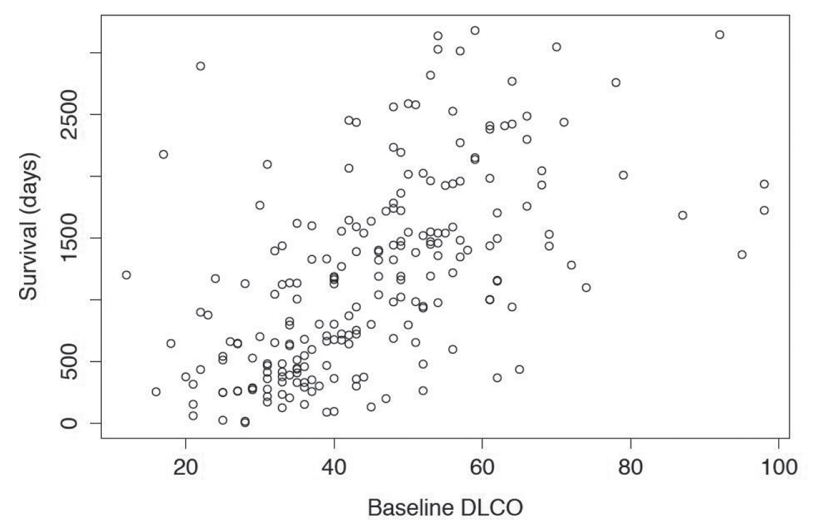

Abstract S21 Figure 1 hypertension were collected retrospectively from 253 IPF patients (in accordance with ATS/ERS criteria and MDT consensus) from a single centre in the UK between $19^{\text {th }}$ April 2007 and $13^{\text {th }}$ November 2014. Lung function including FEV 1 , FVC, DLco and 6 minute walk test (distance, resting and minimum oxygen saturation and maximum heart rate) were collected at baseline, 6 and 12 months of follow up. Survival data were censored at $1^{\text {st }}$ January 2016. The relationship between GAP or CPI and survival was analysed by Spearman's correlation, ROC area under the curve and $\mathrm{Chi}^{2}$ analysis. Multivariate analysis and linear regression were used for the modelling.

Results Of the 253 patients included 188 were male (74\%) with age $71.4 \pm 8.3$ years (mean $\pm \mathrm{SD})$. There were $164(64.8 \%)$ exsmokers and $12(4.7 \%)$ current smokers. At presentation 19 patients had pulmonary hypertension and 35 had evidence of emphysema on HRCT thorax. Baseline lung function $\mathrm{FEV}_{1}$ $79 \pm 22 \%$ predicted, FVC $82 \pm 19 \%$ predicted, DLco $45 \pm 15 \%$ predicted (mean \pm SD). Median survival was 1169 days $\left(3.2\right.$ years). The association between survival and CPI $\left(\mathrm{r}^{2}\right.$ $0.59, \mathrm{p}<0.01)$ or GAP $\left(\mathrm{r}^{2} 0.45, \mathrm{p}<0.01\right)$ was modest. However ROC curve analysis demonstrated that GAP and CPI were poor predictors of survival. $\mathrm{Chi}^{2}$ analysis shows there is no significant difference between these scoring systems. Multivariate analysis demonstrated that baseline $\%$ predicted DLco $\left(\mathrm{r}^{2}=0.32\right.$, $\mathrm{p}=6 \times 10^{-20}$ ) (Figure 1) had the strongest association with survival.

Conclusion Our data suggest that baseline percent predicted DLco may be a better predictor of outcome in patients with IPF. These results required validation by an independent cohort.

\section{Sleep Apnoea: The Big Sleep}

\section{S22 SEVERITY OF SLEEP DISORDERED BREATHING INDEPENDENTLY PREDICTS METABOLIC DYSFUNCTION IN A LARGE POPULATION OF SEVERELY OBESE SUBJECTS: THE ESADA STUDY}

${ }^{1} \mathrm{BD}$ Kent, ${ }^{1} \mathrm{~N}$ Gildeh, ${ }^{1} \mathrm{P}$ Drakatos, ${ }^{2} \mathrm{~L}$ Grote, ${ }^{2} \mathrm{~J}$ Hedner, ${ }^{3} \mathrm{WT}$ McNicholas. 'Guy's and St. Thomas' Hospitals, London, UK; ${ }^{2}$ Sahlgrenska University Hospital, Gothenburg, Sweden; ${ }^{3}$ St. Vincent's University Hospital, Dublin, Ireland

\subsection{6/thoraxjnl-2016-209333.28}

Introduction Obstructive sleep apnoea (OSA) has an established independent association with insulin resistance and type 2 diabetes mellitus (T2DM). However, there are few data examining this relationship in severely obese populations, wherein any detrimental effect of OSA on metabolic health may conceivably be drowned out by the impact of morbid obesity. We assessed the relationship of OSA severity and nocturnal hypoxaemia with metabolic health in a cohort of severely obese patients attending sleep units across Europe.

Methods We performed a cross-sectional analysis of 1,434 participants in the European Sleep Apnea Cohort (ESADA) study with a body mass index (BMI) $\geq 35 \mathrm{~kg} / \mathrm{m}^{2}$, using multivariate regression analysis to assess T2DM prevalence according to OSA severity indices. Patients with diabetes were identified by history and medication prescription, and by screening for undiagnosed diabetes with glycosylated haemoglobin (HbA1c) measurement. The relationship of OSA severity with glycaemic control was assessed in diabetic subjects. Multivariate linear regression and multivariate analysis of co-variance were used to examine the 
relationship of HbA1c levels with OSA severity in both diabetic and non-diabetic patients.

Results In a cohort of predominantly male (63.5\%) and severely obese (mean BMI $40.3 \mathrm{~kg} / \mathrm{m}^{2}$ ) individuals, 32.2\% had T2DM. Although the likelihood of T2DM was significantly greater in the highest AHI quartile than the lowest (unadjusted OR 1.78; 95\% CI: 1.29-2.47), this relationship lost significance following adjustment for anthropometric, demographic, and clinical factors (adjusted OR 1.21; 95\% CI: 0.83-1.76; p = 0.33). However, severity of nocturnal hypoxaemia remained a predictor of T2DM prevalence despite adjustment for confounding factors (adjusted OR for most severe mean nocturnal $\mathrm{SpO}_{2}$ quartile 2.23; 95\% CI: $1.50-2.20 ; \mathrm{p}<0.001)$, as well as predicting the likelihood of poor diabetic control (adjusted OR 1.87; 95\% CI: 1.06-3.30; $\mathrm{p}=0.03$ ). In further analyses, HbA1c levels were independently predicted by OSA severity indices and nocturnal hypoxaemia in both non-diabetic and diabetic subjects, while adjusted mean HbA1c levels were significantly higher in patients with more severe sleep disordered breathing.

Conclusion Metabolic health in severely obese sleep patients appears to be significantly worse in those subjects with more severe sleep disordered breathing, with a particularly strong relationship with the degree of nocturnal hypoxaemia.

\section{S23 NEURAL RESPIRATORY DRIVE DURING SLEEP AT HIGH ALTITUDE}

${ }^{1} \mathrm{~J}$ Steier, ${ }^{2} \mathrm{~N}$ Cade, ${ }^{1} \mathrm{~B}$ Walker, ${ }^{1} \mathrm{~J}$ Moxham, ${ }^{1} \mathrm{CJ}$ Jolley. ${ }^{1}$ King's College London, London, UK; ${ }^{2}$ Francis Crick Institute, London, UK

\subsection{6/thoraxjnl-2016-209333.29}

Introduction Ventilation at altitude changes due to altered levels of pO2, pCO2 and the effect on blood $\mathrm{pH}$. Nocturnal ventilation is particularly exposed to these changes. We hypothesised that increasing neural respiratory drive is associated with the severity of sleep-disordered breathing at altitude.

Subjects and methods British mountaineers were studied at sea level (London, UK), and at altitude at the Aconcagua (Andes, Argentina). Neural respiratory drive (NRD) was measured as electromyogram of the diaphragm (EMGdi) overnight by a transoesophageal multi-electrode catheter (Yinghui Medical Ltd, Guangzhou, China). Following initial assessment with a polysomnography (London, UK), pulse oximetry measured oxygen concentration and oxygen desaturation indices (4\%ODI) at altitude.

Results Four healthy subjects (3male, age 31 (3) years, bodymass-index $23.6(0.9) \mathrm{kg} / \mathrm{m}^{2}$, neck circumference $37.0(2.7) \mathrm{cm}$, $\mathrm{FEV}_{1} 111.8$ (5.1)\% predicted, FVC 115.5 (6.3)\% predicted) were studied. Inspiratory and expiratory muscle strength were normal (PImax 130.7 (29.8) cm $\mathrm{H}_{2} \mathrm{O}$, PEmax (153.3 (38.4) cm $\mathrm{H}_{2} \mathrm{O}$ ). No subject had significant sleep abnormalities at sea level (Total Sleep Time 344.4 (30.5) mins, Sleep Efficiency 86.6 (6.4)\%, Respiratory Disturbance Index 0.8 (0.4)/hour, mean $\mathrm{SpO}_{2} 97.5$ (1.3\%). The oxygen desaturation index increased with the development of periodic breathing at altitude (4\% ODI 22.0 (7.2)/hour at $3,380 \mathrm{~m}, 61.4(26.9) /$ hour at $4,370 \mathrm{~m})$. Average nocturnal SpO2 $(84.8(0.5 \%))$ at $3,380 \mathrm{~m} ; 81.0(4.1 \%)$ at $4,370 \mathrm{~m})$ and nadir oxygenation $(68.1(8.6 \%)$ at $3,380 \mathrm{~m} ; 67.4(7.6 \%)$ at $4,370 \mathrm{~m})$ dropped with altitude. The average EMGdi was 5.2 (19.1\%) max at sea level and increased to 14.1 (3.4\%) at altitude when falling asleep at $4,370 \mathrm{~m}$, and correlated well with the $4 \%$ ODI $(r=0.968, p=0.032)$. EMGdi during the last inspiratory effort prior to central apnoea was $5.1(1.5 \%)$ max, while the first inspiratory effort following central apnoea was 10.5 (3.2\%) max at $4,370 \mathrm{~m}$.

Conclusion The severity of periodic breathing when asleep deteriorates with an increase in altitude, induced by an elevated neural respiratory drive as a response to hypobaric environmental conditions.

\section{S24 A COMPARISON OF PULSE TRANSIT TIME BETWEEN SUBJECTS WITH OBSTRUCTIVE SLEEP APNOEA SYNDROME, NOCTURNAL INSPIRATORY FLOW LIMITATION AND THE ABSENCE OF SIGNIFICANT SLEEP DISORDERED BREATHING}

${ }^{1} \mathrm{~B}$ Chakrabarti, ${ }^{2} \mathrm{~S}$ Emegbo, 'S Craig, ${ }^{1} \mathrm{~N}$ Duffy, ${ }^{1} \mathrm{JF}$ O'Reilly. 'Aintree Chest Centre, Liverpool, UK; ${ }^{2}$ Liverpool Sleep and Ventilation Centre, Liverpool, UK

\subsection{6/thoraxjnl-2016-209333.30}

Introduction Pulse Transit Time (PTT) represents a non-invasive indirect marker of sleep fragmentation in OSAS. Little is known regarding PTT indices in persons presenting with sleepiness where sleep studies exhibit "flow limited" breaths in the absence

Abstract S24 Table 1 Key demographics in the IFL, OSAS and NFL "Control" cohorts

\begin{tabular}{|c|c|c|c|c|c|}
\hline & $\begin{array}{l}\text { Inspiratory flow limitation (IFL) } \\
\text { cohort } \\
(\mathrm{n}=20 \text {; female }=13 \text { ) }\end{array}$ & $\begin{array}{l}\text { Obstructive sleep apnoea syndrome (OSAS) } \\
\text { Cohort } \\
(\mathrm{n}=20 \text {; female }=13)\end{array}$ & $\begin{array}{l}\text { "NFL" } \\
\text { Control group }(n=20 \text {; } \\
\text { female = 13) }\end{array}$ & $f$ Value & $P$ value \\
\hline Age (years) & $47(8.39)$ & $45(8.30)$ & $47(8.79)$ & $F=0.28$ & $P=0.76$ \\
\hline $\begin{array}{l}\mathrm{BMI} \\
(\mathrm{kg} / \mathrm{m} 2)\end{array}$ & $34.25(6.63)$ & $36.31(5.62)$ & $28.90(6.81)$ & $F=7.21$ & $P=0.002$ \\
\hline $\begin{array}{l}\text { AHI } \\
\text { (per hour) }\end{array}$ & $3.84(1.16)$ & $48.93(16.77)$ & $1.01(1.05)$ & $F=152.78$ & $P<0.001$ \\
\hline $\begin{array}{l}\text { RDI } \\
\text { (per hour) }\end{array}$ & $17.71(5.34)$ & $57.22(16.33)$ & $2.63(1.34)$ & $F=159.72$ & $P<0.001$ \\
\hline Oxygen Saturation & $95.05(1.85)$ & $93.75(1.55)$ & $95.90(1.48)$ & $F=10.14$ & $P<0.001$ \\
\hline $\begin{array}{l}\text { Epworth Sleepiness Score (ESS) at } \\
\text { presentation }\end{array}$ & $16.35(3.65)$ & $14.45(5.52)$ & $7.90(6.21)$ & $F=12.49$ & $P<0.001$ \\
\hline Presence of Hypertension & $5 / 20$ & $5 / 20$ & $0 / 20$ & $F=3.16$ & $P=0.05$ \\
\hline Presence of Cardiac Disease & $1 / 20$ & $1 / 20$ & $0 / 20$ & $F=0.5$ & $P=0.61$ \\
\hline
\end{tabular}

